\title{
Malignant Ito Cell Tumor
}

National Cancer Institute

\section{Source}

National Cancer Institute. Malignant Ito Cell Tumor. NCI Thesaurus. Code C80352.

A malignant tumor of the liver composed of hepatic stellate cells. 